\title{
Pathology of the formalin-treated heterograft porcine aortic valve in the mitral position
}

\author{
A LAN G. ROSE \\ Department of Pathology, University of Cape Town Medical School, Observatory, C.P., South Africa
}

\begin{abstract}
The mitral valve was replaced by a pig aortic valve in 33 patients at Groote Schuur Hospital. Eleven of the failed heterograft aortic valves were examined at intervals of from 2 to 32 months after insertion. Fourteen control pig aortic valves were also examined. Electron microscopy was performed on two of the failed heterograft valves and three control pig valves. Failure of the heterograft was due to stretching and deformation of the cusps with resultant valvular incompetence. Stretching of the cusp was a result of reduction in the amount of its collagen content. The elastic tissue appeared little altered. A microscopic layer of fibrin thrombus was present on the surface of 8 of the 11 valves. Only 2 of the 11 valves showed invasion of the graft by immunologically competent cells. No valve showed any sign of infection or calcification. The denatured collagen of the heterograft has a low antigenicity and also, unfortunately, a limited durability.
\end{abstract}

\section{MATERIALS AND METHODS}

Aortic valves were obtained from pigs aged 1 to 2 years and weighing between 150 and $300 \mathrm{~kg}$. After trimming, the valves were mounted according to the method of Ionescu et al. (1968), packed with cotton wool and immersed in $4 \%$ formol-saline (buffered at pH 5.6). The clinical course of these 33 patients has been described by Schrire and Barnard (1970).

The 11 valves were removed at operation and submitted in formalin for pathological examination. Each valve, still mounted on its Dacron cloth-covered titanium ring, was examined with the naked eye for signs of thrombosis, rupture or incompetence. Any other abnormal feature was also noted. Sections taken from the centre of each valve cusp were stained by the haematoxylin and eosin, alcian blue, and elastic van Gieson methods. A series of 14 control pig aortic valves were similarly examined; nine of these valves had been frame-mounted and treated with formalin in a manner identical with those used in the 11 patients.

Electron microscopy was performed on cusp material from two of the failed heterograft valves (cases 2 and 10) and three of the control valves. This was considered worthwhile in studying changes in the collagen, rather than cellular detail, of the formalin-fixed material.

Blocks for electron microscopy, about $2 \mathrm{~mm}$ thick, were cut from the cusps of the valves in such a way as to include the full thickness of the cusp. The blocks were post-fixed in osmic acid (Palade's fixative) for one hour, dehydrated in graded ethanols, and embedded in Araldite. The Araldite-embedded tissue was orientated for sectioning so that the fibrosa of each cusp was included in the section. Ultrathin sections were cut in a Porter-Blum ultramicrotome, stained with uranium acetate (one minute), washed in distilled water, and then stained with Reynold's lead citrate (one minute), followed by a further wash in distilled water. When dry the sections were examined by electron microscopy at magnifications of $\times 40,000$ and $\times 60,000$.

\section{RESULTS}

The patients' ages ranged from 18 to 59 years. The valves had been in situ for periods of from 2 to 32 months. The Table summarizes the main clinical and pathological details of the 11 patients whose heterograft valves were examined. The most significant macroscopic finding was that all cusps showed varying degrees of stretching and deformation with resultant valvular incompetence. No cusp had undergone rupture and no thrombi were seen with the naked eye. The latter finding contrasts with the experimental work in dogs of Gunning and Meade (1971), who noted that pig valves preserved in formalin showed a tendency to thrombus formation in the sinuses of Valsalva. However, microscopically in 8 of the 11 valves a thin layer of platelet and fibrin thrombus was present on the arterialis surface of the cusps.

Microscopically all the grafted valves showed an absence of the original cells of the cusp. Several cusps had a few isolated cells scattered 
T A B L E

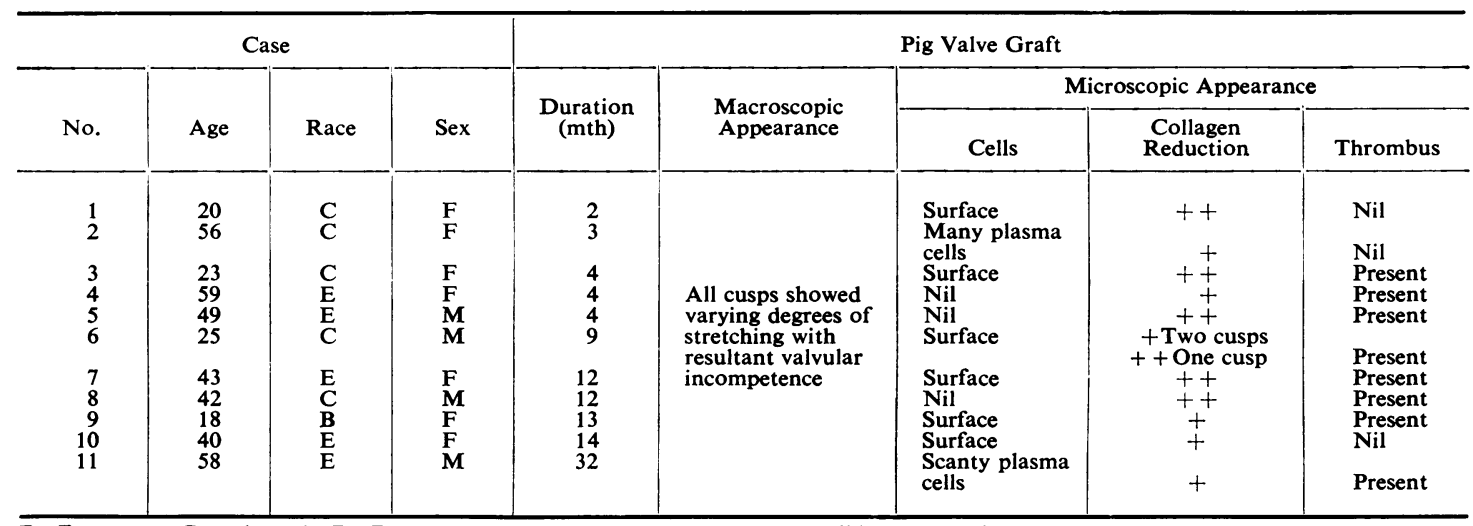

on their surface, often entrapped in the layer of fibrin. A reduction in the amount of collagen of variable degree was noted in each of the 11 valves. The collagen acquired an amorphous hyaline or fibrinoid appearance and stained less intensely with the van Gieson stain. The fibrosa was often no longer distinguishable as a distinct layer within the cusp. A plasma cell response to the graft was noted in two valves only (cases 2 and 11). The pathology of valves which failed early (four months or less) was the same as those failing later (after nine months).

Striking differences were noted when the failed heterograft valves were examined with the naked eye and microscopically in comparison with the control pig valves. The cusps of the control valves (Fig. 1a and b) meet together in a triradiate fashion with a fairly wide area of apposition. The valvular pockets are clearly seen. The contact areas of the cusps lie in a vertical plane at a level superior to that of the supporting metal ring. The microscopical anatomy of the pig aortic valve appears essentially similar to that of the human aortic valve (Welch, 1969). The anatomy of the pig valve differs from that of the normal human aortic valve in that one-third of the animal aortic ring is formed by cartilage and the base of the right coronary cusp is muscular (Binet, Duran, Carpentier, and Langlois, 1965). The 'backbone' of the normal pig aortic valve cusp (Fig. 1c) consists of a layer of compacted collagen fibres called the fibrosa. The remainder of the cusp is composed of loosely arranged collagen and elastic fibres. Moderate numbers of fibroblasts are present.

Figure 2 shows a valve removed from case 1 after two months. It shows a lesser degree of in- competence than many of the other failed valves. Figure 3 shows the histological appearance of a cusp from case 7 . This valve shows changes similar to those seen in case 1 , with the additional finding of a layer of fibrin on the surface of the arterialis aspect of the cusp. This was the usual microscopic appearance in 9 out of the 11 valves.

The host cellular response in 9 of the 11 cases was that of a mild mononuclear cell infiltration at the base of the cusp where it had been in proximity to the host tissue. There was no sign of a host immune response to the acellular, denatured collagen of the cusp in these nine cases. In the remaining two patients (cases 2 and $11)$, the cellular response was more florid and there were indications of a possible immune response on the part of the host as evidenced by the presence of plasma cells and other pyroninophilic cells of lymphoid type. These cells were most numerous at the base of the cusp and appeared to be migrating out along the cusp surface in diminishing numbers towards its free margin. A degree of erosion of the cusp substance was seen in areas. Apart from this response by what appear to be immunologically competent cells, the cusps of these two patients did not appear to show any significant differences from the other nine cases which failed to evoke a similar response. The macroscopic and microscopic appearances of the valve from case 2 are shown (Fig. 4).

There was no sign of infection of any of the grafted valves. Seven cases of infection among 30 orthotopically transplanted human homograft aortic valves sterilized with betapropiolactone were reported by Reichenbach et al. (1968). 


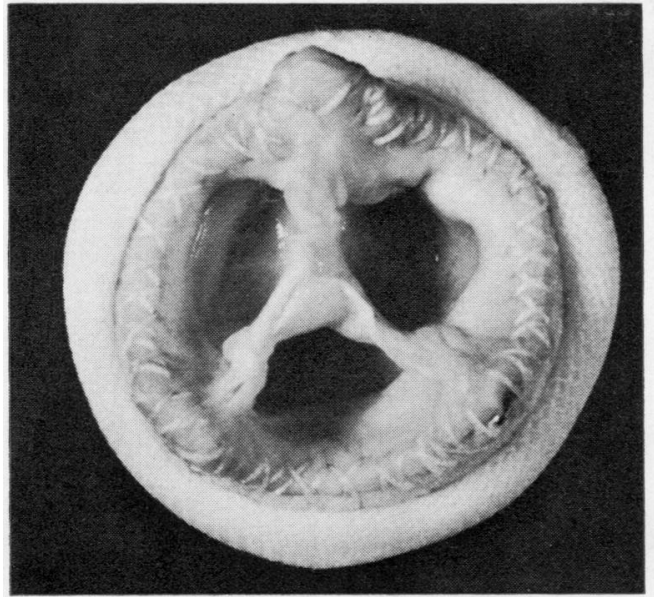

(a)

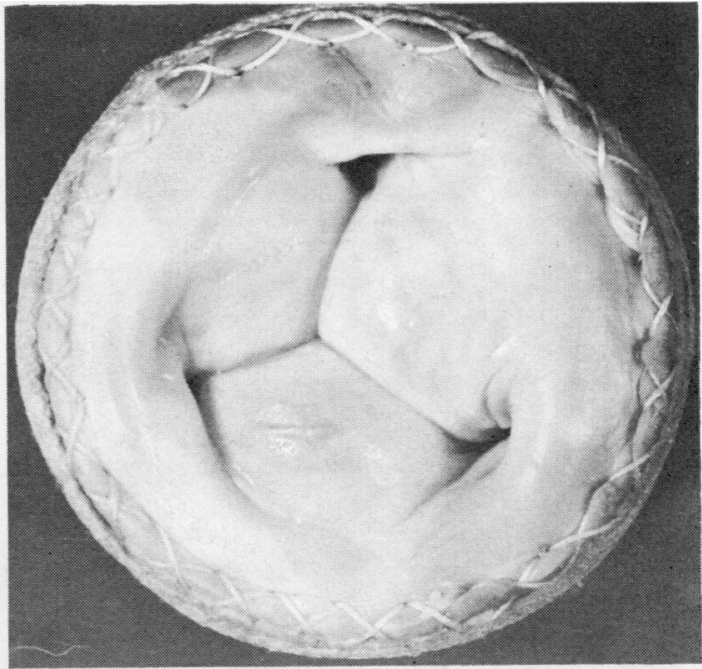

(b)

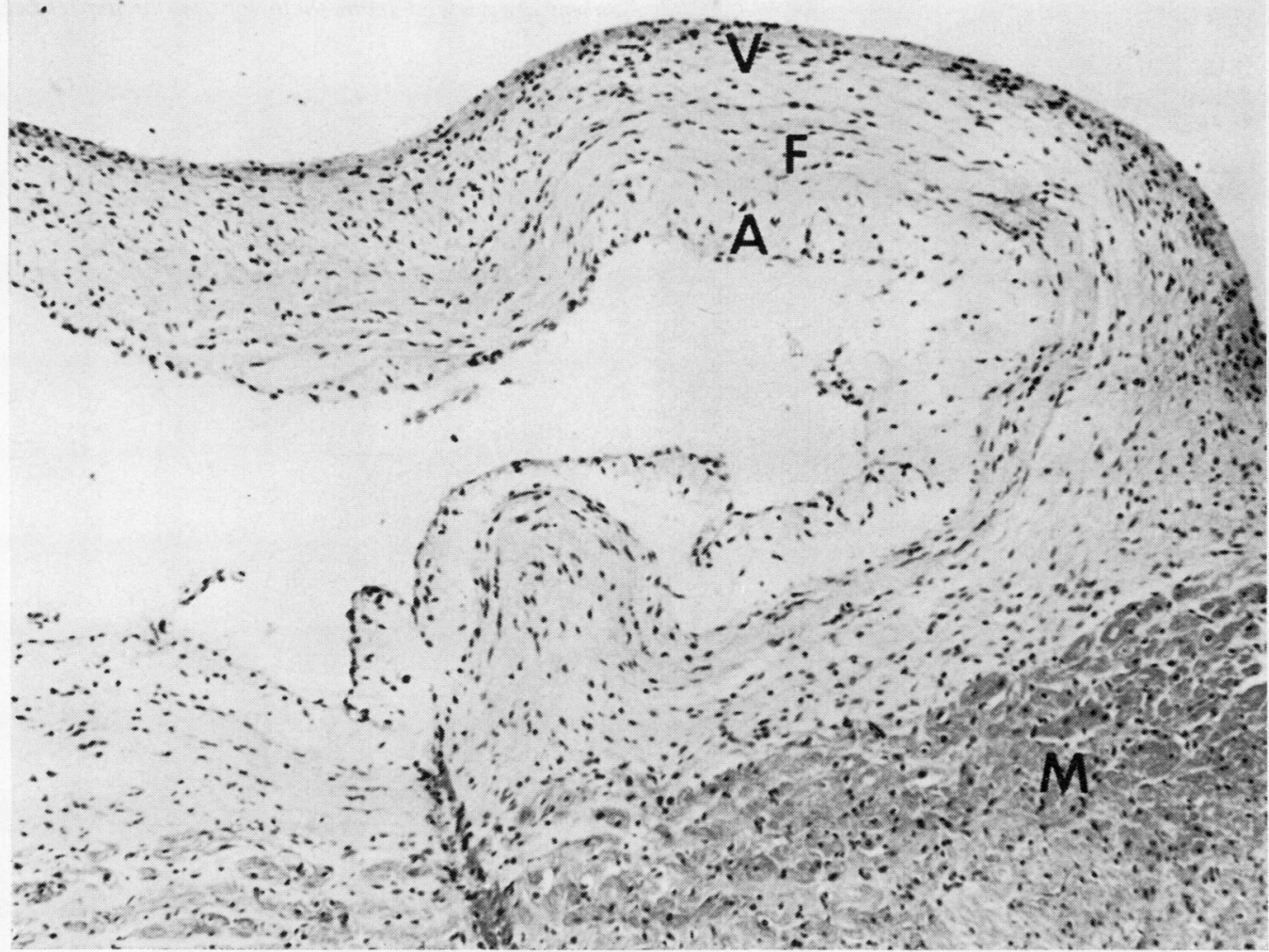

(c)

FIG. 1. (a) Formalin-treated control pig aortic valve mounted on a titanium cloth-covered support $(\times 1 \cdot 5)$. The cusps meet together in a triradiate fashion with a wide area of apposition. (b) The undersurface of the valve is shown (reduced slightly from $\times 2$ ). (c) Microscopical appearance of a cusp from one of the control pig valves. The fibrosa (F) forms the backbone of the cusp and consists of a layer of compacted collagen fibres. The ventricularis $(V)$ and the arterialis $(A)$ lie on the ventricular and aortic aspects of the cusp respectively. They constitute the remainder of the cusp and are made up of loosely arranged collagen and elastic fibres, together with moderate numbers of fibroblast-like cells. The myocardium is indicated $(M)$ (haematoxylin and eosin $\times 20)$. 


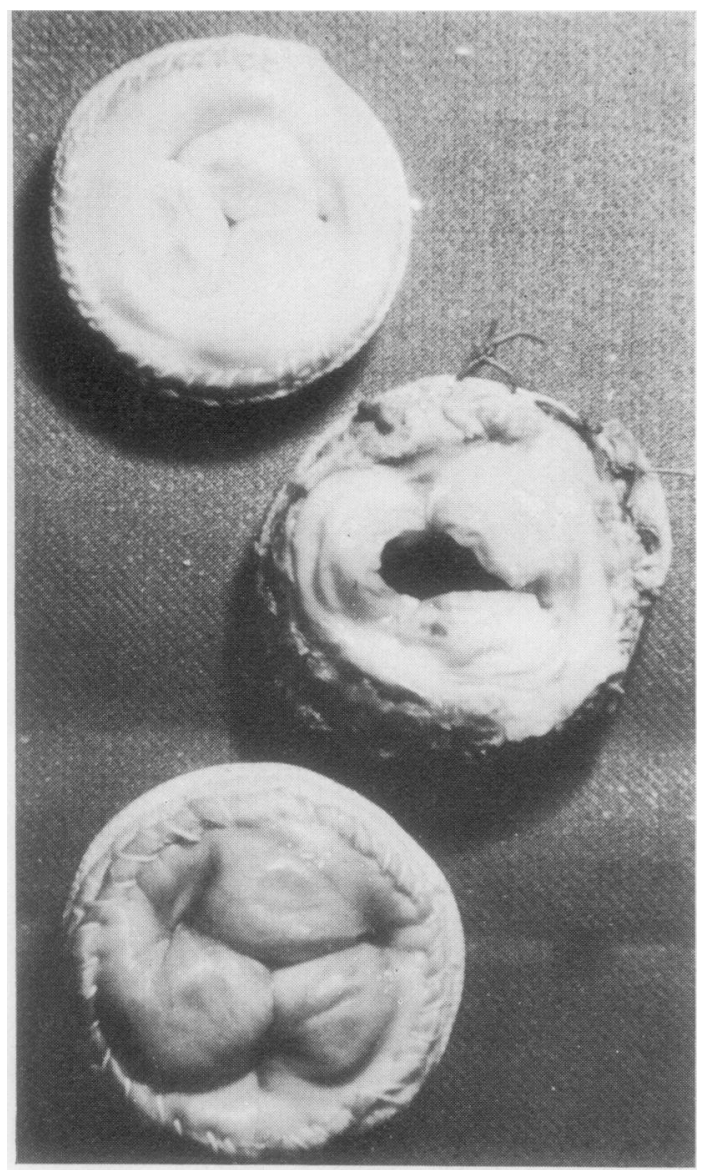

FIG. 2. The valve shown centre was removed from case 1 (Table) after two months. It is an example of one of the less severely incompetent valves. Note how the stretched valve cusps hang down beneath the level of the supporting ring and render the valve incompetent. A control valve is seen on either side. All three valves are viewed from their ventricular aspect (actual size).

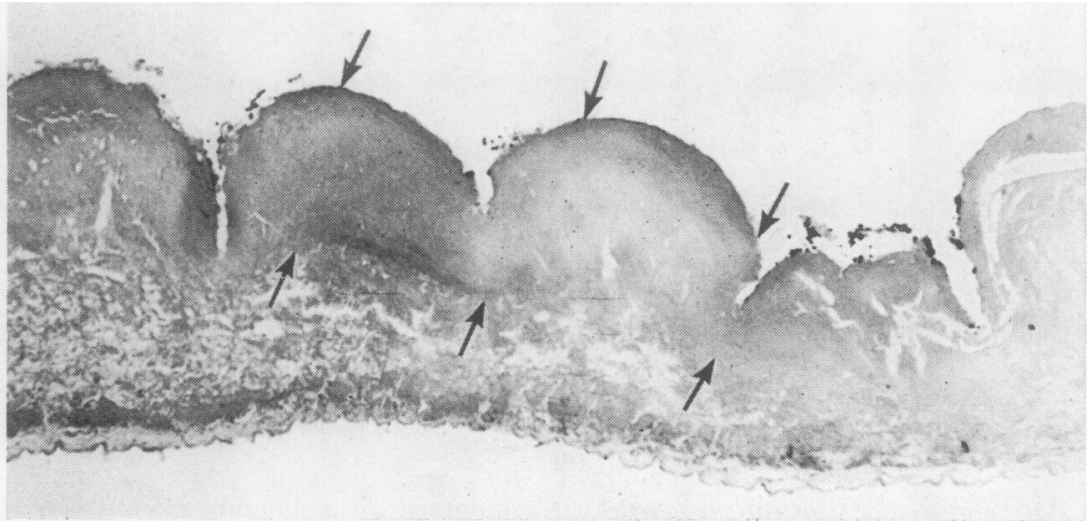

FIG. 3. Histological appearance of a cusp of the failed valve removed from case 7 . Eight of the 11 valves showed a similar microscopic appearance. The cusp is acellular and the collagen has an amorphous appearance and is reduced in amount. The layer of fibrin thrombus (indicated by arrows) on the arterialis aspect is thicker than in many of the other cusps on which it was present (elastic van Gieson $\times 120$ ). 


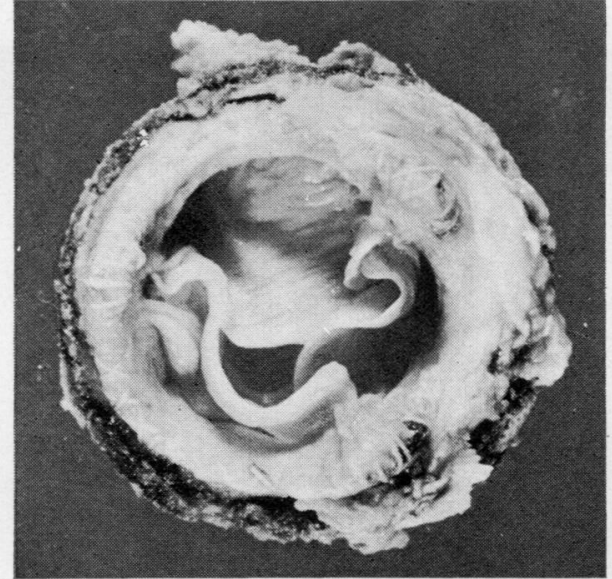

(a)

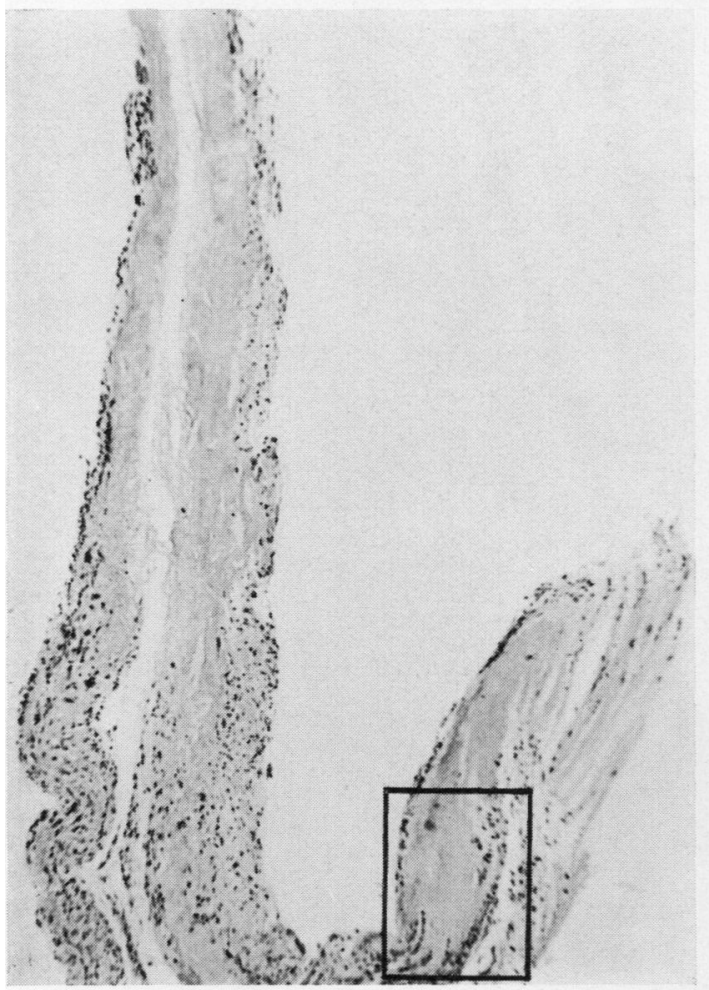

(c)

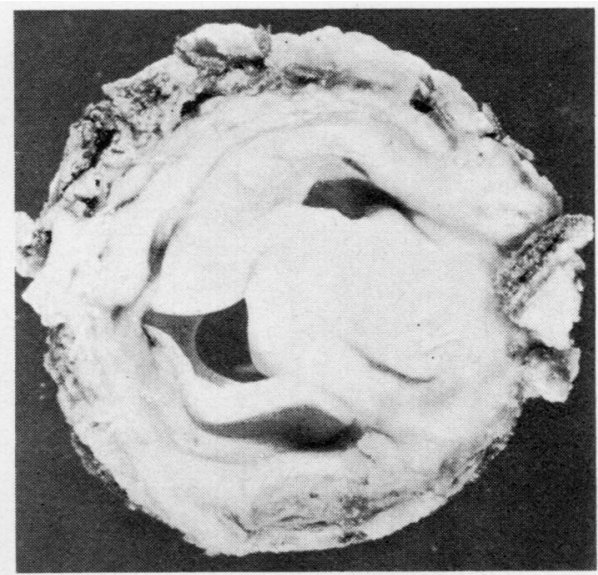

(b)

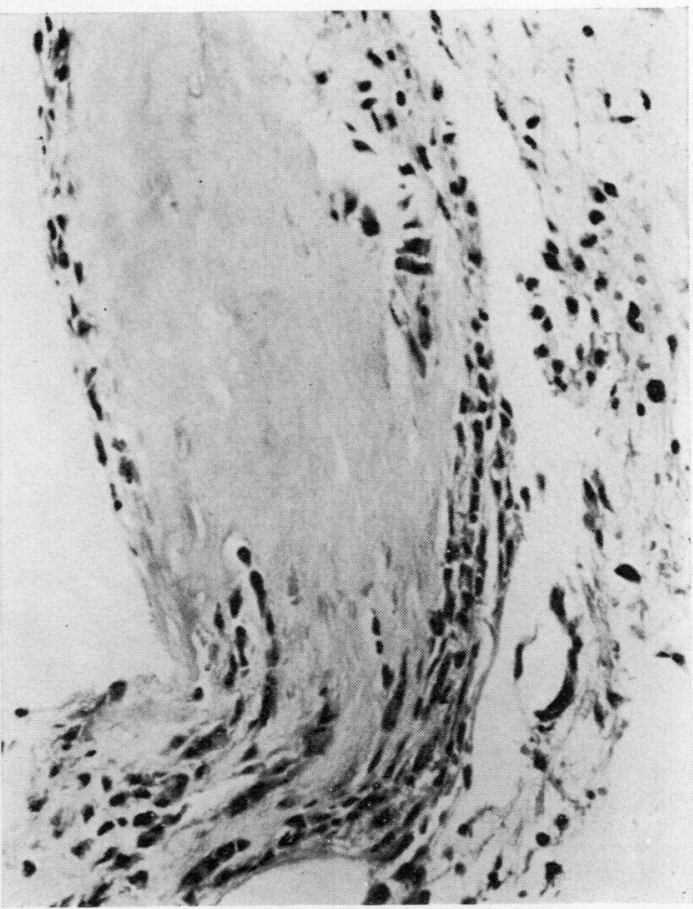

(d)

FIG. 4. ( $a$ and $b)$ The valve removed from case 2. The valve is grossly incompetent due to stretching of its cusps. One cusp is more severely stretched than the other two $(\times 1 \cdot 6)$. (c) Histological appearance of one of the cusps from this valve. Plasma cells and other pyroninophilic cells of lymphoid type are invading the base of the cusp and migrating along the cusp surface in diminishing numbers towards its free margin (haematoxylin and eosin $\times 32$ ). (d) The area shown within the square at a higher power. The cells are eroding the acellular denatured collagen of the heterograft (haematoxylin and eosin $\times 320$ ). 


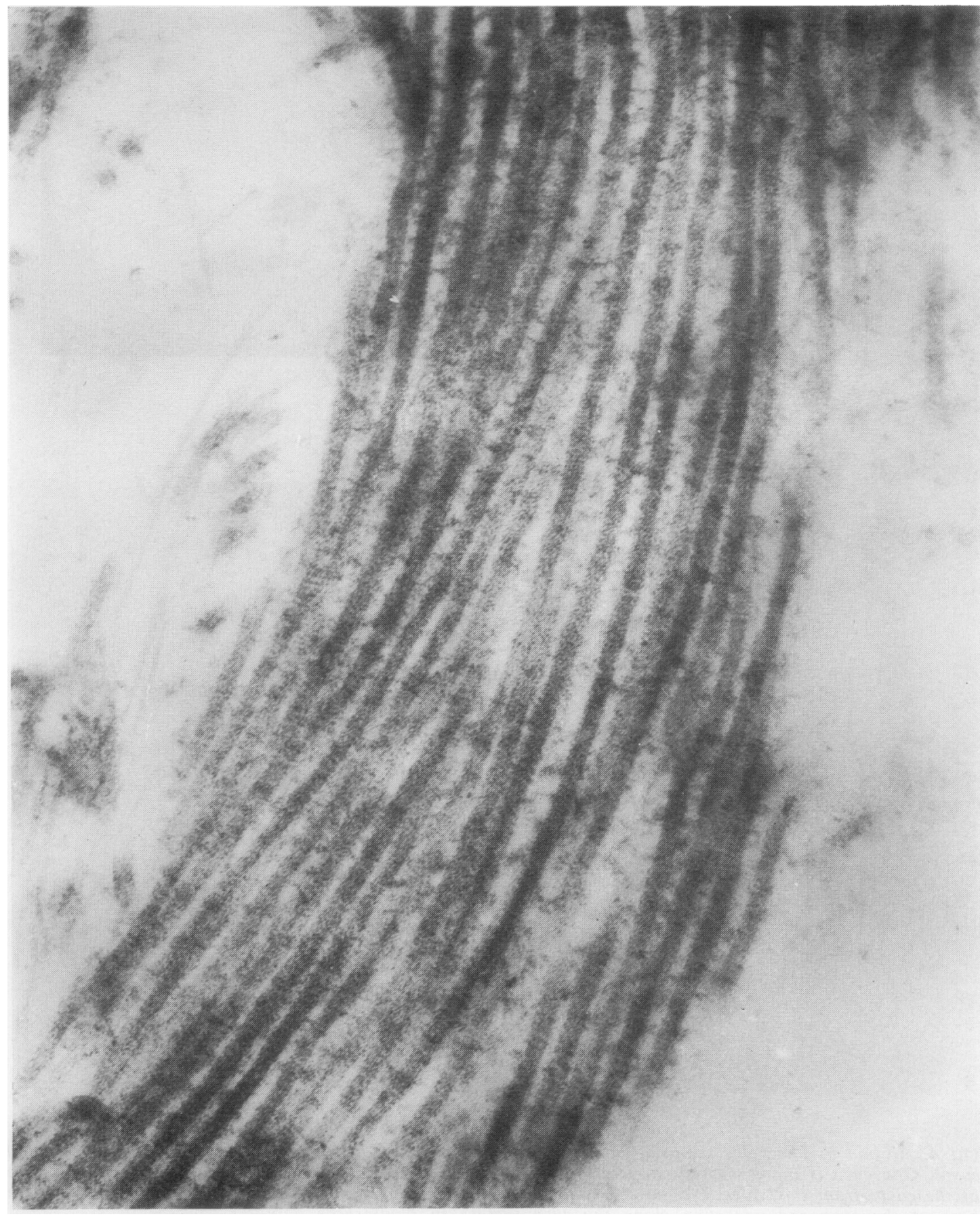

FIG. 5. Collagen fibres of one of the control valves. Preservation is poor, but the fibres are structurally intact. Regular periodicity is observed in some of the fibres (electron photomicrograph $\times 127,000$ ). 


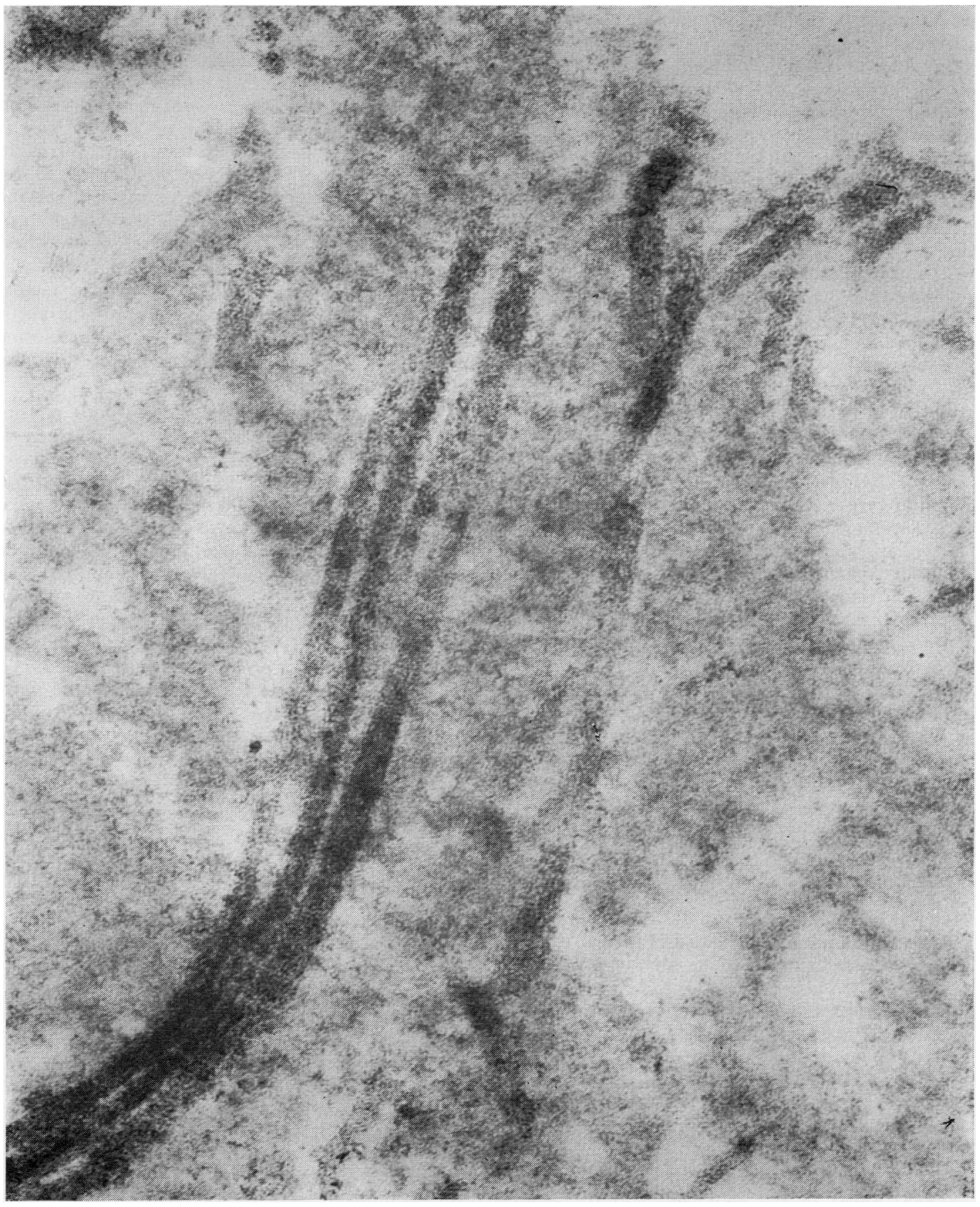

FIG. 6. Collagen fibres in the valve from case 2. The poorly preserved collagen fibres seem to 'fade out' and merge with amorphous, finely granular material (electron photomicrograph $\times 190,000)$. 
Davies et al. (1968) encountered infection in some of their early aortic homografts treated with steroids.

In contrast to the collagen, the elastic tissue of the heterograft valve cusps had a relatively normal appearance. No abnormality of acid mucopolysaccharide was noted in any of the valves, and abundant amounts of this substance were seen in the region of the valve ring in both the failed valves and the control pig aortic valves. None of the valves showed any sign of calcification.

Electron microscopy of the control pig valves revealed that the collagen fibres were poorly preserved, but their structural integrity appeared to be intact and a regular periodicity was still discernible in some of the fibres (Fig. 5). The collagen fibres seen by electron microscopy of the valve cusps from case 10 had an appearance similar to that of the controls. However, electron microscopy of the collagen present in the valve of case 2 (one of the two valves eliciting an immune response) revealed that the poorly preserved collagen fibres in many areas seemed to 'fade out' and merge with amorphous, finely granular material lying between fibres which were still intact (Fig. 6). Periodicity was discernible in very few of the fibres. While it is tempting to speculate that one is demonstrating disintegration of collagen fibres, there is no proof that this granular material is derived from collagen. However, material of similar appearance was described by Perez-Tamayo (1970) in extracellular collagen resorption in carrageenin granulomas. Fibril separation was not noted in our material. In a recent paper on connective tissue abnormalities in spontaneous rupture of the chordae tendineae (Caulfield, Page, Kastor, and Sanders, 1971), electron microscopy of areas of total loss of collagen revealed finely granular material in the region normally occupied by well orientated bundles of collagen. In view of these findings, there appears to be an increased likelihood that the amorphous, finely granular material noted in case 2 is derived from the destruction of collagen fibres.

\section{DISCUSS:ON}

Stretching of the valve cusps was the cause of the incompetence of the 11 failed aortic valve grafts. Tearing of the valves was not noted. The changes noted in the collagen seem to be most significant. The denatured collagen of the heterograft has a low antigenicity and limited dura- bility. Progressive weakening of a valve subjected to an abnormal degree of stress is thus likely. A similar problem involving stretching of aortic valve cusps was mentioned by Davies et al. (1968) in a report of their findings in homograft replacement of the aortic valve. In the discussion of a paper by Carpentier et al. (1969), Kay is quoted as saying that 'all transplant valves in patients six months or more who come to reoperation or autopsy ... demonstrated varying degrees of stretching of the leaflets, attenuation of the tissues, fragmentation and laceration regardless of the method of preservation or whether it was a homograft or heterograft. One of the factors for failure may well be the inability of the aortic valve to withstand the greater ventricular closing pressures over a prolonged period without becoming stretched.'

While there are many instances, both physiological and pathological, in which collagen is rapidly destroyed (Montfort and Perez-Tamayo, 1961; Lazarus et al., 1968; Perez-Tamayo, 1970) it appears unnecessary to postulate active collagenolysis of the valvular collagen of the failed heterografts. The inert (and denatured) collagen in the transplanted pig valve does not have an infinite durability. No living cells are present within the valve substance, thus no new collagen can be produced. The destruction of the valvular collagen is a function of time, augmented perhaps by the increased mechanical stress the valve is subjected to in the mitral position. Gunning and Meade (1971) feel that once the valve cusps are thickened or changed by preservation then turbulence ensues. If turbulent flow is present the natural deterioration that occurs in preserved valve cusps may well be accelerated. Treatment of the pig valve in formalin certainly renders the cusps more rigid than they are in the fresh state.

The use of formalin ( $4 \%$ formol-saline) is an easy means of attaining bacteriological sterility as well as attenuation of antigenicity of the valvular collagen. Ionescu et al. (1968) postulated that calcification would be less prone to occur due to the low $\mathrm{pH}$ inside the formalin-treated transplant. Our results appear to confirm this, as the absence of calcification was a constant finding in each of the 11 heterografts examined in the present series. This contrasts with the relatively frequent observation of calcification in aortic homograft valves transplanted in the fresh state (Smith, 1967; Davies et al., 1968). Mohri, Reichenbach, Barnes, and Merendino (1967) found foci of apparently reversible mineraliza- 
tion in fibrin deposits on homograft aortic cusps in the dog; the valves had been transplanted fresh and still contained living donor cells. Whether the $\mathrm{pH}$ within the cusps of the formalintreated transplant would remain low for many months is doubtful as the valve is in intimate contact with the circulating blood. Another possible explanation for the lack of calcification may be that formaldehyde acts as a tanning substance by combining readily with the epsilon-amino group of the lysine residues in collagen with the formation of a methylol compound (International Review of Connective Tissue Research, 1964). These groups, which are important in tissue mineralization such as calcification, may thus be blocked by the action of the formaldehyde.

The absence of any significant immune response in 9 of the 11 transplanted valves agrees with the findings of O'Brien and Clareborough (1967) who quote Nossal and MacKay's (personal communication) suggestion that the reason for this lies in the nature of the cusp tissue, which is low in cell membrane elements, contains denatured protein, and is a non-living graft. Collagen possesses a low antigenicity. Hirsch (1967) suggested that autograft, homograft, and heterograft valves should all behave similarly in failing to evoke a destructive immunological or inflammatory response in the host. Our findings in 9 of the 11 valves confirm this with regard to heterograft valves. The reason for the plasma cell response in the remaining two valves is unexplained.

Apart from the lack of durability, the porcine heterograft aortic valve has several advantages over the prosthetic valve, especially with regard to operative mortality, thromboembolism, and bacterial endocarditis. It was hoped that a living autologous fascia lata valve would retain the advantages of the pig valve, while possessing a greater inherent durability by virtue of its living fibroblasts. However, recent reports (Lincoln et al., 1971; Welch, Potvliege, and Primo, 1971) reveal that the autologous fascia lata valve is imperfect. Depletion of fibroblasts and degenerative changes in the collagen of the transplanted fascia have been noted. Insufficiency of the implanted valve together with thromboembolic complications were frequent. Neither the heterograft valve nor the fascia lata valve is a suitable alternative for the prosthetic heart valve.

My thanks go to Mr. J. Dale and Mr. M. Emms for the electron photomicrographs and to Professor C. J. Uys for helpful advice and criticism.

\section{REFERENCES}

Binet, J. P., Duran, C. G., Carpentier, A., and Langlois. J. (1965). Heterologous aortic valve transplantation. Lancet, 2, 1275.

Carpentier, A., Lemaigre, G., Robert, L., Carpentier, S., and Dubost, C. (1969). Biological factors affecting longterm results of valvular heterografts. J. thorac. cardiovasc. Surg., 58, 467.

Caulfield, J. B., Page, D. L., Kastor, J. A., and Sanders, C. A. (1971). Connective tissue abnormalities in spontaneous rupture of chordae tendineae. Arch.Path.,91, 537.

Davies, H., Missen, G. A. K., Blandford, G., Roberts, C. I., Lessof, M. H., and Ross, D. N. (1968). Homograft replacement of the aortic valve. A clinical and pathologic study. Amer. J. Cardiol., 22, 195.

Gunning, A. J., and Meade, J. B. (1971). Preservation and function of heterologous aortic valves. An experimental study. Thorax, 26, 179.

Hirsch, H. H. (1967). Persistence of aortic-valve homografts. Lancet, 1, 1225.

Ionescu, M. I., Wooler, G. H., Whitaker, W., Smith, D. R., Taylor, S. H., and Hargreaves, D. H. (1968). Heart valve replacement with reinforced aortic heterografts. J. thorac. cardiovasc. Surg., 56, 333.

International Review of Connective Tissue Research (1964). Edited by D. A. Hall. Vol. 2, p. 293. Academic Press, New York.

Lazarus, G. S., Daniels, J. R., Brown, R. S., Bladen, H. A., and Fullmer, H. M. (1968). Degradation of collagen by a human granulocyte collagenolytic system. J. clin. Invest., 47, 2622.

Lincoln, J. C. R., Riley, P. A., Revignas, A., Geens, M., Ross, D. N., and Ross, J. K. (1971). Viability of autologous fascia lata in heart valve replacements. Thorax, 26, 277.

Mohri, H., Reichenbach, D. D., Barnes, R. W., and Merendino, K. A. (1967). A biologic study of the homologous aortic valve in dogs. J. thorac. cardiovasc. Surg., 54, 622.

Montfort, I., and Perez-Tamayo, R. (1961). Studies on uterine collagen during pregnancy and puerperium. Lab. Invest., 10, 1240.

O'Brien, M. F., and Clareborough, J. K. (1967). Heterograft aortic-valve replacement. Lancet, 1, 929.

Perez-Tamayo, R. (1970). Collagen resorption in carrageenin granulomas. ii. Ultrastructure of collagen resorption. Lab. Invest., 22, 142.

Reichenbach, D., Mohri, H., Dillard, D., Wintersheid, L., and Merendino, K. A. (1968). Pathologic changes in human aortic valve homografts. Circulation, Suppl. vi to $37,38,163$.

Schrire, V., and Barnard, M. S. (1970). The fate of the porcine aortic xenograft in the mitral position. Cardiovasc. Res., Suppl., 279.

Smith, J. C. (1967). The pathology of human aortic valve homografts. Thorax, 22, 114.

Welch, W. (1969). A comparative study of different methods of processing aortic homografts. Thorax, 24, 746.

- Potvliege, P., and Primo, G. (1971). Autologous fascia lata cardiac valve replacement. Thorax, 26, 271. 